\title{
RADAR OBSERVATIONS OF VENUS IN 1962
}

\author{
By J. E. B. PONSONBY, J. H. THOMSON \\ and $\mathbf{K}$. S. IMRIE,
}

Nuffield Radio Astronomy Laboratory, Jodrell-Bank.

\begin{abstract}
RÉsumé. - Résultat d'observations effectuées à Jodrell-Bank au grand radio-télescope.

Abstract. - Results of observations made at Jodrell-Bank with the radio-telescope.

Zusammenfassung. - Ergebnisse der mit dem Radio-Teleskop in Jodrell-Bank gemachten Beobachtungen.

Резюме. - Результаты наблюдений совершенных на радиотелескопе станции жодрэлл-Банг.
\end{abstract}

A continuous wave radar system at 4 1 $0.2 \tilde{5} \mathrm{Mc} / \mathrm{s}$ has been developed with a $10 \mathrm{~kW}$ transmitter and a receiver with eleven integrating channels in frequency, each of $\mathrm{I} \mathrm{c} / \mathrm{s}$ bandwidth at $\mathrm{I} \mathrm{c} / \mathrm{s}$ spacing. The central frequency of the receiver is digitally controlled to follow a computed frequency ephemeris to about o.I c/s. This equipment has been used on the 8o-metre radio-telescope at Jodrell-Bank to obtain radar echoes from Venus during the six weeks following the close approach of $\mathrm{r}_{962}$ November i 3. The total Doppler frequency shift caused by the relative motion of Jodrell-Bank and Venus was measured to $\pm 0.2 \mathrm{c} / \mathrm{s}$ and was over $3 \mathrm{o} \mathrm{kc} / \mathrm{s}$ by the end of the observations; comparison of this observed shift with the predicted values gives a value of the astronomical unit of $149596600 \pm 900 \mathrm{~km}$, in agreement with other radar determinations. An upper limit of $\mathrm{r} \mathrm{c} / \mathrm{s}$ has been placed on the width between the half-power points of the frequency spectrum of the returned signals 
throughout the period of the observations. Discussion of this result shows that the rotational period is probably of the same order of magnitude

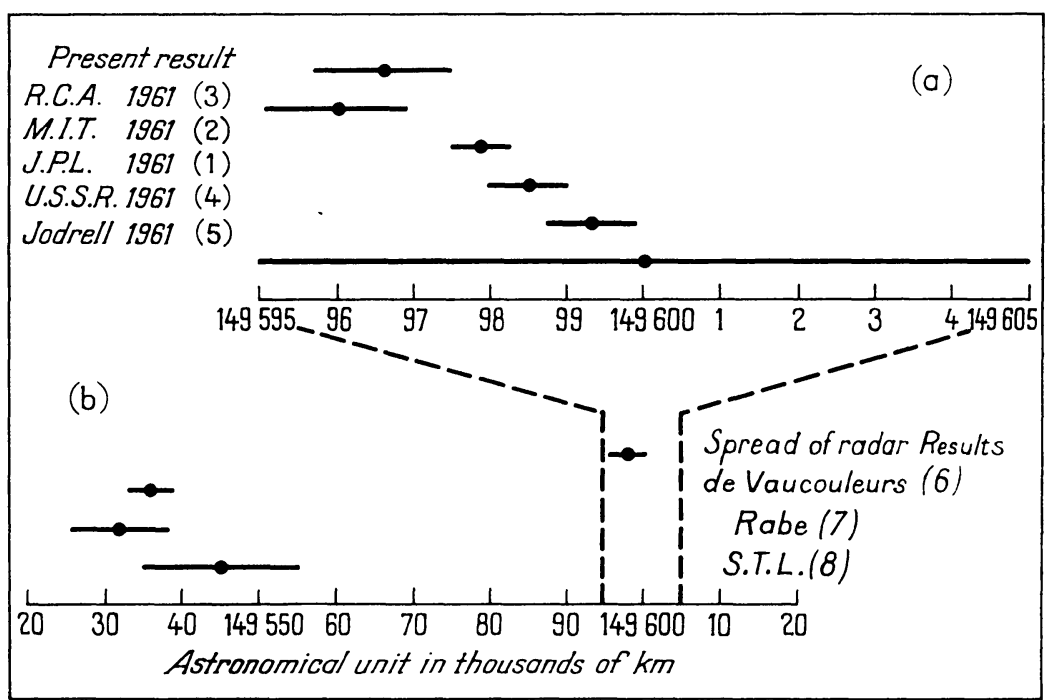

Fig. 1 .

(a) The present result and recent radar determinations of the astronomical unit.

(b) The total spread of radar results compared with recent astronomical determinations. De Vaucouleurs' value is a best estimate from a critical survey of all results excluding radar methods. Notice that the scale changes by a factor of 10 between $(a)$ and $(b)$.

as the orbital period. The contribution of the second order term to the measured Doppler frequency shift was up to $\mathrm{r} .2 \mathrm{c} / \mathrm{s}$ and was clearly detected. 